A $\mathrm{C}$ publications J. Chem. Metrol. 14:2 (2020) 114-124

journal of chemical metrology

\title{
Impact of test conditions on the bacterial bioassay in the presence of $\mathrm{TiO}_{2}$ nanoparticles
}

\author{
Asli Baysal ${ }^{\oplus}{ }^{*}$, Hasan Saygin $\oplus^{2}$ and Gul Sirin Ustabasi $\oplus^{3}$ \\ ${ }^{1}$ Health Services Vocational School of Higher Education, T. C. Istanbul Aydin University, Sefakoy \\ Kucukcekmece, 34295, Istanbul, Türkiye \\ ${ }^{2}$ Application and Research Center for Advanced Studies, T. C. Istanbul Aydin University, Sefakoy \\ Kucukcekmece, 34295, Istanbul, Türkiye \\ ${ }^{3}$ Graduate School of Science Engineering and Technology, Istanbul Technical University, Maslak \\ Istanbul, Türkiye
}

(Received May 09, 2020; Revised May 22, 2020; Accepted June 01, 2020)

\begin{abstract}
To assess the fate and behavior of engineered nanoparticles in the aquatic environment, it is crucial to conduct appropriate bacterial bioassay procedure. However, test conditions of bacterial bioassay are limitedly investigated; especially in the field of environmental media chemistry or aging of nanoparticles which interfere the procedure. For this purpose, $\mathrm{TiO}_{2}$ nanoparticles were treated with different test conditions by keeping them in $1 \%$ and $100 \%$ seawater for one day and 20 days. The bacterial bioassay of treated nanoparticles towards gram-negative (Pseudomonas aeruginosa) and gram-positive (Staphylococcus aureus) bacteria were examined, as well as the mechanism by biochemical responses of bacteria and physicochemical properties of $\mathrm{TiO}_{2}$ nanoparticles. The viability response of tested bacteria reduced remarkably in seawater concentration, while treatment (aging) duration of tested nanoparticles slightly affected the viability response of tested bacteria. Moreover, key events which affected the bioassay response were changed with the treatment duration and media concentration. The results also showed that aging duration and concentration of the media influenced the main physicochemical properties due to the alterations in surface from aging media compared to unaged ones.
\end{abstract}

Keywords: Nanoparticles; bacteria bioassay; interference; nanometrology; surface analysis; ecotoxicology. ( $)$ 2020 ACG Publications. All rights reserved.

\section{Introduction}

Nanoparticles (NPs) have found widespread application in consumer products, medicine, technology, etc. Especially, titanium dioxide $\left(\mathrm{TiO}_{2}\right)$ is one of the most common NPs due to its unique physicochemical properties [1,2]. Their numerous uses will eventually lead to their entry into the aquatic environment, either direct or indirect process, transport, or use [3].

\footnotetext{
*Corresponding author E-Mail: aslibaysal@aydin.edu.tr
} 
Numerous studies have evaluated the ecological impact of $\mathrm{TiO}_{2} \mathrm{NPs}$ in the aquatic environment using various organisms including bacteria, algae, invertebrates, and fish [2-5]. In the majority of these previous studies, $\mathrm{TiO}_{2}$ NPs were freshly suspended in aquatic systems by various methods. In the meantime, the size, shape, and composition of NPs can change with time upon exposure to the aquatic environment [6]. Although their ecological impact might be affected by these properties, there has been very little attention to the test conditions which cause interferences on the procedure [5]. However, to understand the effect of test conditions on the NPs toxicity, there has no standard procedure, as well as there is no consensus in the scientific community to study regarding various conditions that have potential to interfere the procedure response. On the other hand, it is known that environmental fate and effects on environmental biota of NPs change before, during and after the testing. In the meantime, changes in the composition and chemical configuration before, during and after the testing have a major impact on the properties of the material [7,8]. Additionally, precise test condition has important role to obtain the desired information during the procedure. Besides, to obtain reliable test procedure, different challenges exist respecting stable exposure condition and characterizing. In this field, exposure or treatment duration in environmentally relevant medium exclusively need attention. It is indicated that long-term exposure and its identification and qualification of the effects is therefore of high regulatory relevance [8]. On the other hand, to examine the long-term exposure or exposure duration effect, a few limited toxicological studies are existed. They suggested that the aged NPs showed different toxicities compared to the unaged ones. Moreover, it is known that the occurrence and distribution of NPs in the environment lead to the interaction with chemicals which originated natural or anthropogenic sources in the environment [1,3-7]. The interaction between NPs and chemicals were evaluated in several studies and depending on the type of NPs and tested chemicals, NPs fate was changed [1,3-7]. Moreover, in most of these eco-studies, aging solutions/media were not environmentally relevant media. Artificial or ultra-pure water was applied to the NPs during the aging process as an environmental media [2,9,10]. Additionally, in most of these studies, aging was relatively lower duration (approx. hours to 10 days) and applied only on the rutile form of $\mathrm{TiO}_{2}$ NPs [2,9-12]. Furthermore, to understand the environmental impact of the NPs during aging, different additives or spiked chemicals were used to reflect environmental components. This method is frequently applied for model studies. However, chemical compounds can be found as chelates under natural conditions, and artificial additives might not reflect the natural condition. Moreover, isolation of specific compounds from the environmental media is mostly impossible. Thus, dilution of the real environmental media can be an appropriate approach to understand and reflect the environmental condition.

Therefore, in this study, we investigated the impact of the various test conditions, environmental media chemistry and aging of NPs, on the bioassay responses of gram-negative and gram-positive bacteria.

\section{Experimental}

\subsection{Materials and Methods}

In this study, two commercial $\mathrm{TiO}_{2} \mathrm{NPs}$ with different forms (anatase and rutile) were analyzed, and provided by Nanografi-Turkey. Anatase (Ti-A) and rutile (Ti-R) form $\mathrm{TiO}_{2} \mathrm{NPs}$ were $99.5 \%$ and $99.9 \%$ purity and $5 \mathrm{~nm}$ and $45 \mathrm{~nm}$, respectively. Selected gram-negative Pseudomonas aeruginosa (P. aeruginosa) and gram-positive Staphylococcus aureus (S. aureus) were obtained from American Type Culture Collection (ATCC).

Seawater was taken from Florya, Istanbul-Turkey. Seawater solutions as an environmental media were prepared in two concentrations $(1 \%$ and $100 \%)$ with ultra-pure water. The procedures of chemical analysis to characterize the environmental media are summarized in Supplementary Table 1 and results of the seawater are shown in Supplementary Table 2.

\subsection{Aging Procedure}

The aging procedure consisted of preparing various suspensions of $\mathrm{TiO}_{2} \mathrm{NPs}_{\text {separed in different }}$ concentrations of seawater in $20 \mathrm{~mL}$ sample vials. Then samples were kept under laboratory conditions and vigorously shaken with shaker $[1,3,6,7] . \mathrm{TiO}_{2} \mathrm{NPs}$ were separated from the solution media by 
centrifugation after certain aging durations (1 day and 20 days). Separated NPs were dried in a furnace at $70^{\circ} \mathrm{C}$ and they were used in further physicochemical characterization and toxicity analysis. The $\mathrm{pH}$ of the solution was not change during both aging durations with checking the $\mathrm{pH}$ various time intervals.

\subsection{Bacterial Bioassay Procedure}

To examine the toxicological behavior of aged $\mathrm{TiO}_{2} \mathrm{NPs}$, freshly cultured bacteria (P. aeruginosa and $\mathrm{S}$. aureus) were exposed to $25 \mathrm{mg} / \mathrm{mL} \mathrm{TiO}_{2} \mathrm{NPs}$ in nutrient broth medium. They were incubated in a dark oven at $37^{\circ} \mathrm{C}$ for $24 \mathrm{~h}$. Growth inhibition was measured by optical density measurement, which is a widely applied method in the literature [12-15]. In this method, turbidity caused by bacterial growth was measured at $600 \mathrm{~nm}$ after $24 \mathrm{~h}$ incubation (exposure) time. Controls for toxicity assessment did not contain any type of $\mathrm{TiO}_{2} \mathrm{NPs}$, they only contained isolated bacteria suspended in broth. All samples had five replicates. Averages of those five replicas are reported in the results, figures, and tables. Error bars in the results represent the standard deviation of their five measurements.

\subsection{Biochemical responses of Tested Bacteria}

Biochemical responses were measured immediately after the $24 \mathrm{~h}$ period from the incubated bacteria harvested from the broth. Samples were placed in the wells of 96-well plates so that their OD600 measurements and biochemical assays can be conducted simultaneously.

Total protein concentration was measured by the Bradford method using bovine serum albumin as the standard. Control and sample solutions were measured at $595 \mathrm{~nm}$ using a UV-VIS spectrophotometer (Thermo Scientific MULTISKAN GO, Finland).

Lipid peroxidase enzyme activities of bacteria exposed to $\mathrm{TiO}_{2} \mathrm{NPs}$ were measured according to the method described in the work of Arora et al. [16]. Method involves the addition of TRIS buffer, ferrous sulfate and ascorbic acid to the bacterial solution that was exposed to $\mathrm{TiO}_{2} \mathrm{NPs}$ (or non-exposed bacterial solution in case of control). After incubation at $37^{\circ} \mathrm{C}$ for $15 \mathrm{~min}$, thiobarbutiric acid was added to the mixture and kept in a $100^{\circ} \mathrm{C}$ water bath for another $15 \mathrm{~min}$. Obtained reaction mixtures were centrifuged and obtained supernatants were placed in wells and measurements were taken at $532 \mathrm{~nm}$ with the UV-Vis spectrometer (Thermo Scientific MULTISKAN GO, Finland).

Total antioxidant capacities of samples were conducted according to the CUPRAC method described in the work of Apak et al. [17]. Briefly, sample solutions were mixed with $0.01 \mathrm{M} \mathrm{CuCl}_{2}, 7.5 \times 10^{-}$

${ }^{3} \mathrm{M}$ Neocuproine, and $1 \mathrm{M} \mathrm{CH}_{3} \mathrm{COONH}_{4}$ and measurements were taken at $450 \mathrm{~nm}$, after the $30 \mathrm{~min}$ waiting period. Trolox was used as a standard.

Finally, superoxide dismutase (SOD) enzyme activity was analyzed as described by Kono [17]. Method involves the addition of Triton X-100, nitro blue tetrazolium, and hydroxylamine-hydrochloric acid, and quantifies the inhibition of photochemical reduction of nitro blue tetrazolium chloride caused by SOD activity. SOD activity was monitored for $5 \mathrm{~min}$ with $1 \mathrm{~min}$ intervals at $560 \mathrm{~nm}$.

\subsection{Physicochemical Characterization of $\mathrm{TiO}_{2} \mathrm{NPS}$}

The surface chemistry of $\mathrm{TiO}_{2} \mathrm{NPs}$ was investigated using Fourier-transform infrared (FTIR) spectrometry (VERTEX 70 ATR, Bruker, Germany). The FTIR analysis was acquired in the range of 4000 to $650 \mathrm{~cm}^{-1}$ to examine the impact of aging and seawater concentration on surface chemistry of $\mathrm{TiO}_{2}$ NPs $[19,20]$.

Particle sizes and zeta potentials of aged $\mathrm{TiO}_{2} \mathrm{NPs}$ aged in different concentrations of seawater were measured via Dynamic light scattering (DLS) using Zetasizer Nano ZS instruments (Malvern, UK) at $25^{\circ} \mathrm{C}$ at a scattering angle of $173^{\circ}$ using a $4 \mathrm{~mW}$ He-Ne laser. Control (unaged) and $\mathrm{TiO}_{2} \mathrm{NPs}$ were sonicated for 5 minutes and placed in standard zeta potential disposable capillary cells and polystyrene cuvettes for zeta potential and size measurements, respectively $[21,22]$. 


\section{Results and discussion}

\subsection{Effect on the Response of Bacterial Bioassay}

Due to the lack of suitable and standard methodologies, the influence of test conditions (e.g. treatment duration (aging) and environmental media chemistry) on the bacterial bioassay response is rarely investigated [23]. However, bacteria have a vital role in the environment and living systems. As well, the bacteria model system is a good indicator to examine the environmental changings or any contaminants released to the environment [1,3,7,19-23]. To understand the impact of aging duration and seawater concentration as test conditions of procedure, bioassay responses of gram-negative ( $P$. aeruginosa) and gram-positive ( $S$. aureus) bacteria to $\mathrm{TiO}_{2} \mathrm{NPs}$ were investigated (Figure 1). The viabilities of tested bacteria were significantly decreased when $\mathrm{TiO}_{2} \mathrm{NPs}$ were aged in different concentrations of seawater. However, aging duration has no or slight effect on the the bacterial bioassay response of NPs.In the one day aging, the viability of gram-positive $S$. aureus was decreased with the increased concentration of seawater. The viability decrease was significant in the Ti-A, however there was no significant changes in the Ti-R. With the 20-days aging, the viability of $S$. aureus was not changed and it was affected neither by the test media nor the form of $\mathrm{TiO}_{2} \mathrm{NPs}_{\text {. }}$

The viability of gram-negative $P$. aeruginosa was different from tested gram-positive bacteria, and the concentration of test media affected the viability; it significantly increased with increasing concentration of seawater. Moreover, aging duration did not significantly influence the bioassay response, while there had a slight trend with aging duration that increased aging reduced the viability of $P$. aeruginosa.
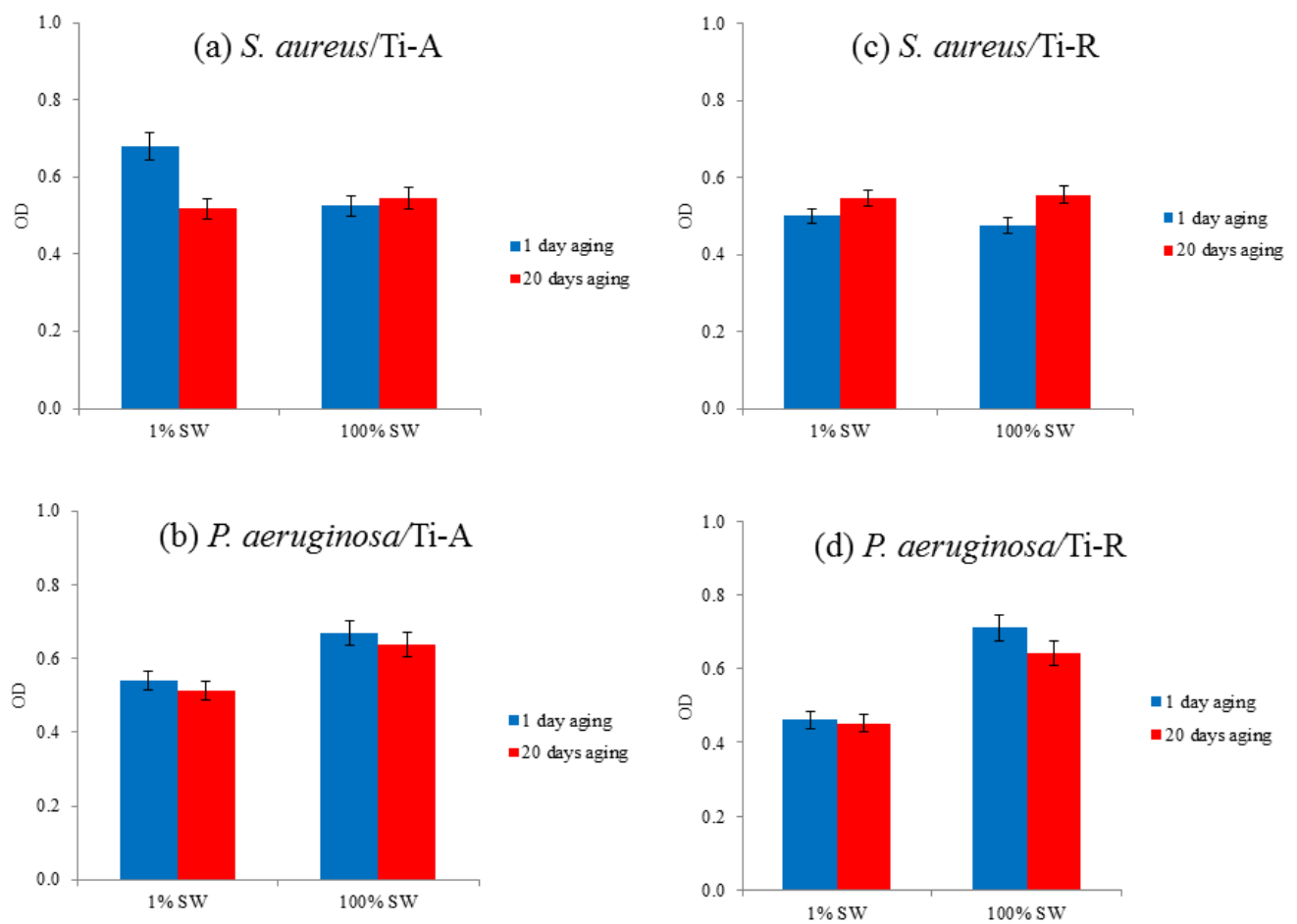

Figure 1. Bacterial bioassay response at different concentrations of seawater and aging duration $(n=5)$ 


\subsection{Effect on the Physicochemical Properties of $\mathrm{TiO}_{2} \mathrm{NPS}$}

It is known that toxicity response of NPs affected by the physicochemical transformations of NPs. However, the literature has rare studies that investigated the test conditions or analytical methodology. For example, Baysal et al. [1,7] examined the effect of sample pretreatments on the bacterial bioassay response of various NPs. These studies indicated that sample pretreatment method influenced the physicochemical properties of NPs. On the other hand, these studies did not examine the treatment duration and environmental media chemistry which can also influence the bacterial response. To examine aging on the physicochemical changes of anatase and rutile form of $\mathrm{TiO}_{2} \mathrm{NPs}$ under various concentrations of seawater, surface chemistry, particle size, and zeta potentials were analyzed. FTIR spectra of control and aged $\mathrm{TiO}_{2} \mathrm{NPs}$ in various concentrations of seawater in the $650-4000 \mathrm{~cm}^{-1}$ region are shown in Figure 2. The characteristic functional groups on the control surfaces of anatase and rutile form of $\mathrm{TiO}_{2} \mathrm{NPs}$ are slight band at 3100-3500 $\mathrm{cm}^{-1}$ and slight peak $1640 \mathrm{~cm}^{-1}$ ascribed $\mathrm{O}-\mathrm{H}$ and $\mathrm{N}-\mathrm{H}$ groups, respectively. The surface chemistry of anatase and rutile form of NPs was changed with aging in seawater. In Ti-A, the intensities of characteristic peaks increased with aging and seawater concentration. Increased concentration of seawater affected the surface with respect to both increasing intensities of characteristic peaks and the alteration of new functional groups. For example, S-related groups at 1200 and $2085 \mathrm{~cm}^{-1}$ were introduced to the surface of Ti-A NPs.
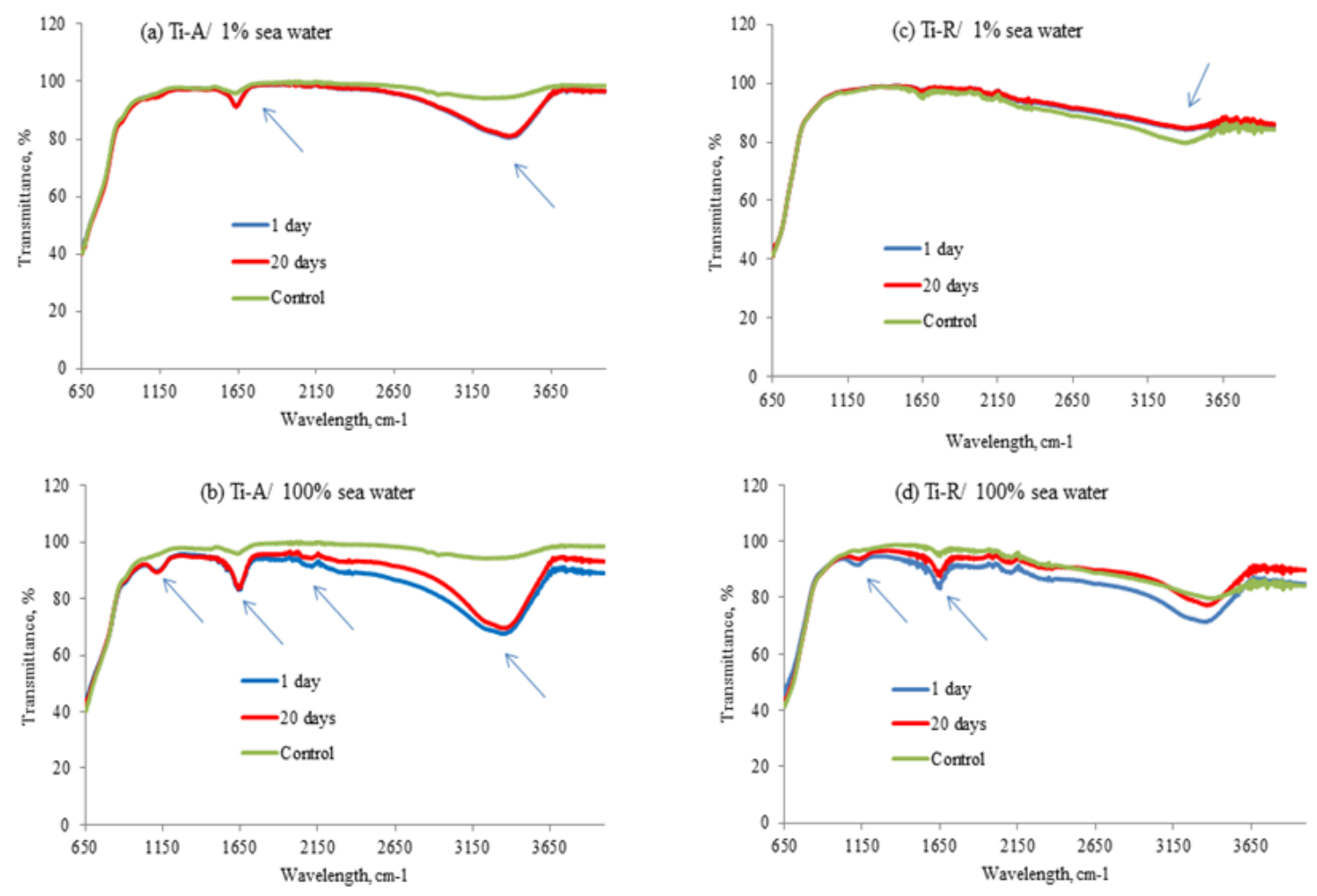

Figure 2. FTIR spectra of the control 'fresh' and 1 day and 20 days aged of $\mathrm{TiO}_{2} \mathrm{NPs}$ in seawater, (a) Anatase form of $\mathrm{TiO}_{2} \mathrm{NPs}$ in $1 \%$ concentration of seawater, (b) Anatase form of $\mathrm{TiO}_{2} \mathrm{NPs}$ in $100 \%$ concentration of seawater, (c) Rutile form of $\mathrm{TiO}_{2} \mathrm{NPs}$ in $1 \%$ concentration of seawater, (d) Rutile form of $\mathrm{TiO}_{2} \mathrm{NPs}_{\text {in }} 100 \%$ concentration of seawater. 
In the meantime, with increased seawater concentration, rutile form showed similar behavior with anatase and new functional group (S-related groups at 1200 and $2085 \mathrm{~cm}^{-1}$ ) was attached to the surface, but intensities of existing functional groups were not to dramatically change compared to anatase form. Also surface chemistries of Ti-R were not affected by the aging at low concentration (1\%) of seawater. On the other hand, aging duration mostly did not influence the surface chemistries of $\mathrm{TiO}_{2} \mathrm{NPs}$, except for aging at high concentration of seawater, in which the intensities of both $\mathrm{TiO}_{2} \mathrm{NPs}$ decreased. In the study of Lu et al. [9], various surface chemistry behaviour was observed among $\mathrm{TiO}_{2} \mathrm{NPs}$, such as alteration of chemical groups or intensities of existing chemical groups, after aging $\mathrm{TiO}_{2} \mathrm{NPs}_{\text {for }} 10$-days in dark and under light. Each tested NPs showed different surface chemistry variations. Changes in the surface chemistry were also examined in another study and results showed that surface chemistry was transformed by aging [24].

The hydrodynamic size of the control and aged $\mathrm{TiO}_{2} \mathrm{NPs}$ were also studied (Table 1). The sizes of aged NPs in various concentrations of seawater were significantly different from the control. Moreover, increasing the aging duration decreased the particle size of Ti-A. However, the particle size of Ti-R increased with the aging. Additionally, similar results were obtained for the seawater concentration: high concentration of seawater decreased the particle size of Ti-A compared to low concentration of seawater, and particle size of Ti-R increased with the high concentration of seawater compared to the low concentration of seawater.

The effect of seawater aging on the zeta potentials of $\mathrm{TiO}_{2} \mathrm{NPs}$ at different seawater concentrations and aging durations is summarized in Table 1. Zeta potentials were also significantly different from control. Moreover, the aging duration at different concentrations of seawater was effective on the zeta potentials. As expected, there was a high correlation between zeta potentials and particle sizes. The changes in zeta potentials might be caused by the changes in surface chemistries with aging durations and environmental media chemistry. It was also observed that the Ti-A particles were more stable with increased aging and seawater concentration, regarding their zeta potentials. Contrarily, Ti-R particles were more stable with short aging duration and low seawater concentration. Changings on the zeta potentials and particle sizes were also observed by other studies related with $\mathrm{TiO}_{2} \mathrm{NPs}$ and the results indicated that decreasing trend during the aging process was attributed to the change in the surface structural degradation, and surface properties of aged ones were no longer as same as the unaged ones $[2,9,10]$. On the other hand, the rutile form $\mathrm{TiO}_{2} \mathrm{NPs}$ was the most used form in previous studies, but anatase form was not tested crystalline form of $\mathrm{TiO}_{2} \mathrm{NPs}$ in the available studies [2,9-12]. Increased zeta potentials and decreased particle size of anatase form of $\mathrm{TiO}_{2}$ NPs can be explained by the alteration of new chemical groups on the surface.

To evaluate the measurement quality which includes reproducibility and repeatability, the standard deviations of the tested physicochemical parameters were compared [1,7] and there has no significant differences.

Table 1. Particle sizes and zeta potential of different form of $\mathrm{TiO}_{2} \mathrm{NPs}$ with the aging in various concentrations of seawater $\left(\mathrm{N}=3, \mathrm{SW}\right.$ : Seawater, Ti-A: anatase form of $\mathrm{TiO}_{2} \mathrm{NPs}$, Ti-R: rutile form of $\mathrm{TiO}_{2} \mathrm{NPs}$ ).

\begin{tabular}{|c|c|c|c|c|c|}
\hline \multirow[t]{3}{*}{ NPs } & \multicolumn{5}{|c|}{ Particle size of $\mathrm{TiO}_{2} \mathrm{NPs}$} \\
\hline & \multirow{2}{*}{$\begin{array}{l}\text { Control } \\
\text { (unaged) }\end{array}$} & \multicolumn{2}{|c|}{$1 \% \mathrm{SW}$} & \multicolumn{2}{|c|}{$100 \% \mathrm{SW}$} \\
\hline & & 1day aged & 20days aged & 1day aged & 20days aged \\
\hline Ti-A & $1038 \pm 96$ & $333 \pm 18$ & $256 \pm 24$ & $273 \pm 11$ & $148 \pm 9$ \\
\hline \multirow[t]{2}{*}{ Ti-R } & $353 \pm 32$ & $291 \pm 21$ & $419 \pm 35$ & $443 \pm 44$ & $978 \pm 81$ \\
\hline & \multicolumn{5}{|c|}{ Zeta potentials of $\mathrm{TiO}_{2} \mathrm{NPs}$} \\
\hline \multirow[t]{2}{*}{ NPs } & Control & $1 \% \mathrm{SW}$ & & $100 \%$ SW & \\
\hline & (unaged) & 1day aged & 20days aged & 1day aged & 20days aged \\
\hline Ti-A & $-3.8 \pm 0.2$ & $-0.1 \pm 0.01$ & $-15.7 \pm 1.1$ & $-10.7 \pm 1.0$ & $-14.3 \pm 1.3$ \\
\hline Ti-R & $-27.5 \pm 2.2$ & $-14.0 \pm 1.0$ & $-11.0 \pm 0.6$ & $-12.1 \pm 0.9$ & $-10.1 \pm 0.7$ \\
\hline
\end{tabular}




\subsection{Effect on the Biochemical Properties of Bacteria}

The test conditions can affect the physicochemical properties of NPs and bacterial bioassay response. As well as, the biochemical pathways of bacteria responses can be influenced by the test conditions. These key bio-events are also important to observe the changings on the method caused from the test conditions.. Therefore, to understand how the biochemical properties of gram-positive and gramnegative bacteria were affected by the test conditions, some main biochemical responses (protein, antioxidant activity, SOD and LPO) of bacteria were investigated. The protein content of the tested bacteria is shown in Figure 3, and these were significantly affected, except for, S. aureus to Ti-R at a high concentration of seawater, P. aeruginosa at a high concentration of seawater in the presence of Ti-A and $P$. aeruginosa at both concentrations of seawater in the presence of Ti-R.

(a) S. aureus/Ti-A

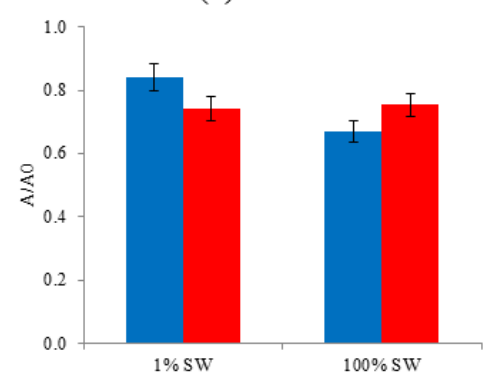

(b) P. aeruginosa/Ti-A

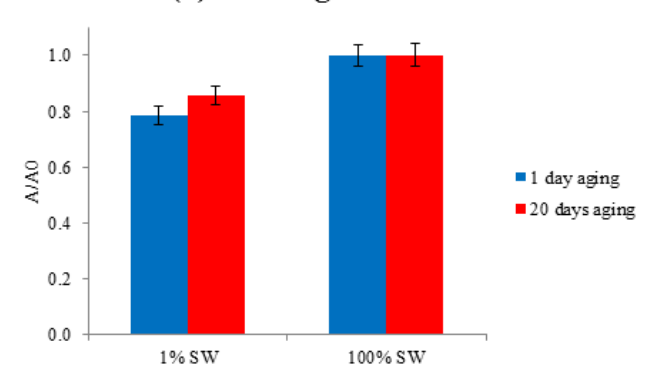

(c) S. aureus/Ti-R

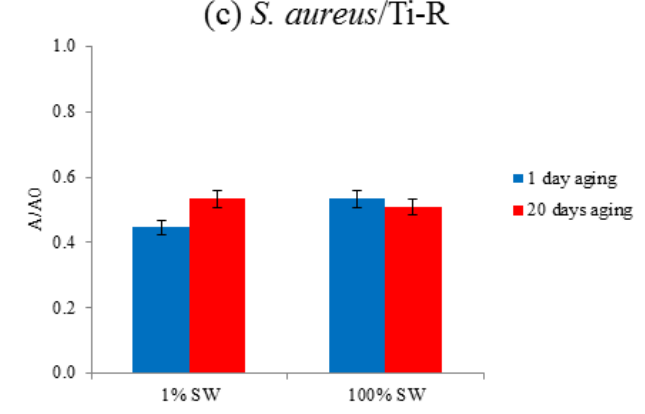

(d) P. aeruginosa/Ti-R

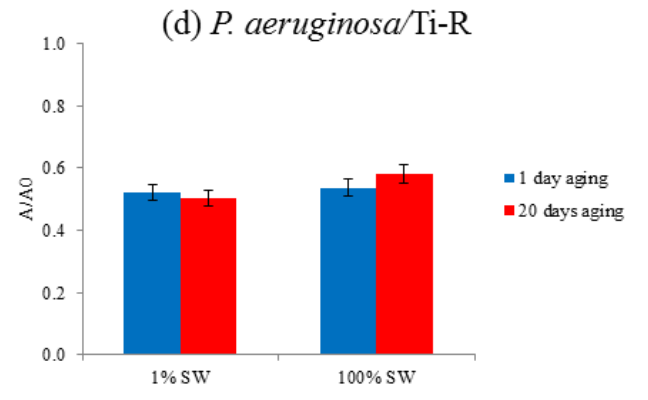

Figure 3. Protein responses of gram-negative and gram-positive bacteria to $\mathrm{TiO}_{2} \mathrm{NPs}_{\text {s }}$ with respect to age at different concentrations of seawater $(n=5)$.

Also, there were high correlations between protein content and viability of tested bacteria with the Ti-A at both aging duration and aging media concentrations. However, the correlation was shown for the Ti-R to the viability at the low concentration of seawater. Furthermore, antioxidant responses were evaluated in Figure 4. A high correlation was observed with S. aureus against Ti-A in both aging durations and concentrations between the viabilities and antioxidant responses. In the meantime, while antioxidant responses were slightly reduced in other cases, there were no correlations with viabilities of tested bacteria or differences to the aged $\mathrm{TiO}_{2} \mathrm{NPs}$. As shown in Figure 5, similar results were observed for the SOD activities. 
(a) $S$. aureus $/ T i-A$

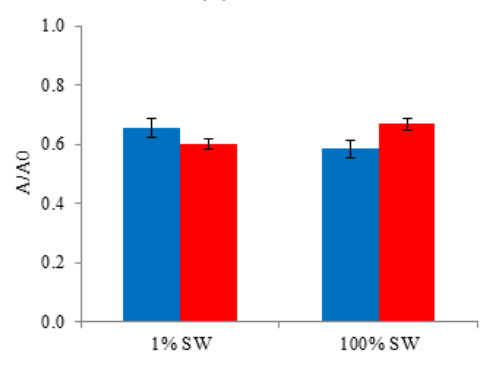

(b) P. aeruginosa/Ti-A

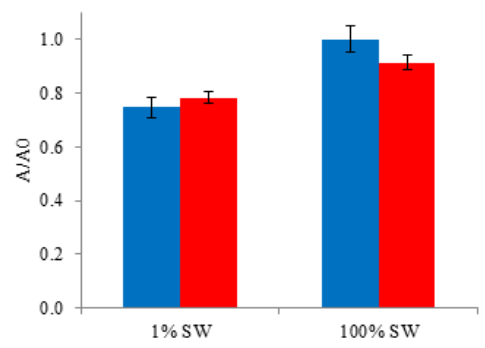

(c) $S$. aureus/Ti-R

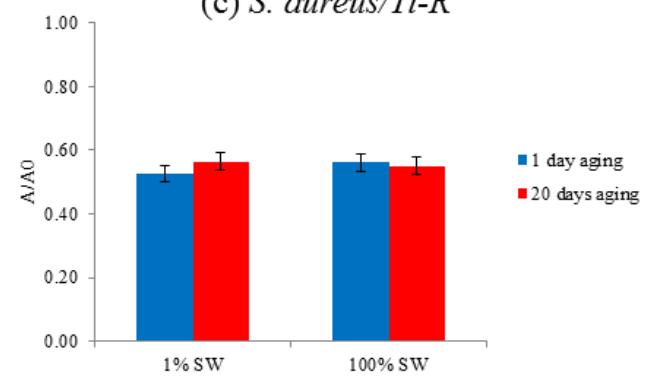

(d) P. aeruginosa/Ti-R

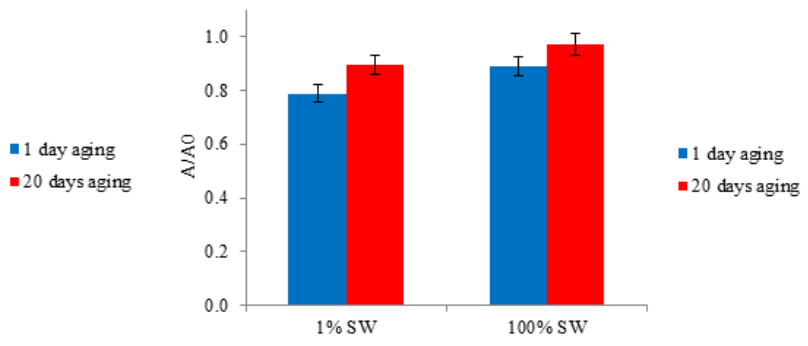

Figure 4. Antioxidant responses of gram-negative and gram-positive bacteria to $\mathrm{TiO}_{2} \mathrm{NPs}$ with respect to age at different concentrations of seawater $(n=5)$.

(a) $S$. aureus/Ti-A

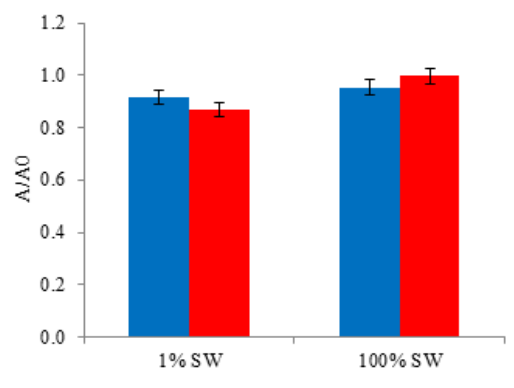

(b) P. aeruginosa/Ti-A

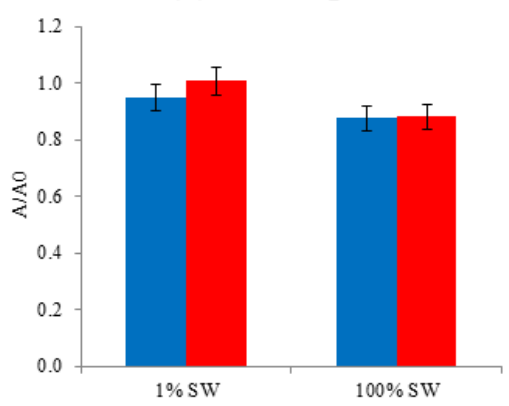

(c) $S$. aureus $/$ Ti-R

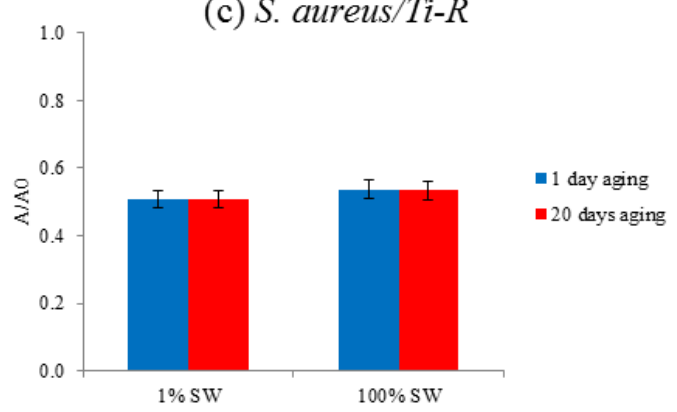

(d) P. aeruginosa/Ti-R

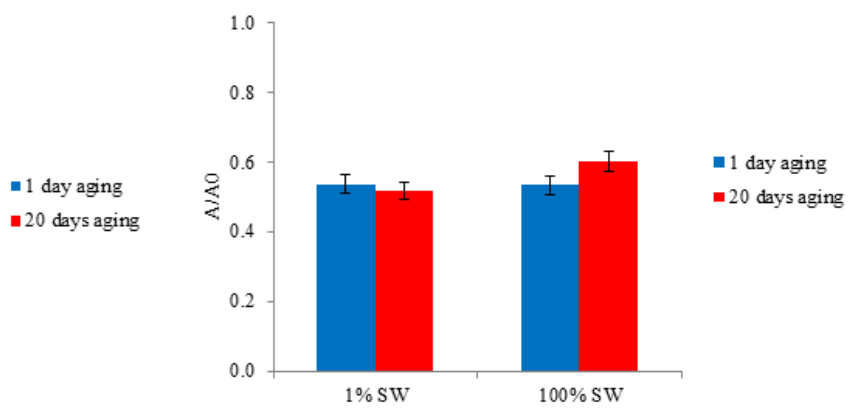

Figure 5. SOD responses of gram-negative and gram-positive bacteria to $\mathrm{TiO}_{2} \mathrm{NPs}$ with respect to age at different concentrations of seawater $(n=5)$. 
Moreover, the response from the lipid metabolism was examined by LPO activities of tested bacteria (Figure 6). Results showed that there was a high correlation with viability and LPO activities, except for S. aureus exposed to Ti-A at high concentration of seawater and P. aeruginosa against exposed Ti-R at high concentration of seawater.

(a) S. aureus/Ti-A

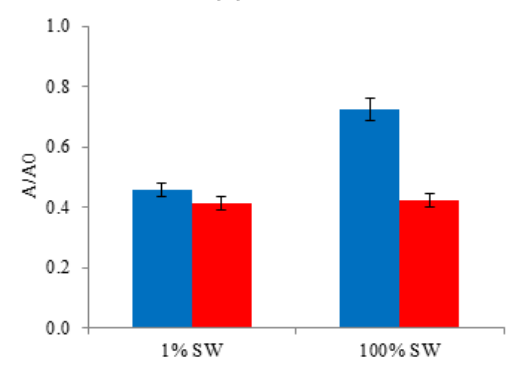

(b) P. aeruginosa/Ti-A

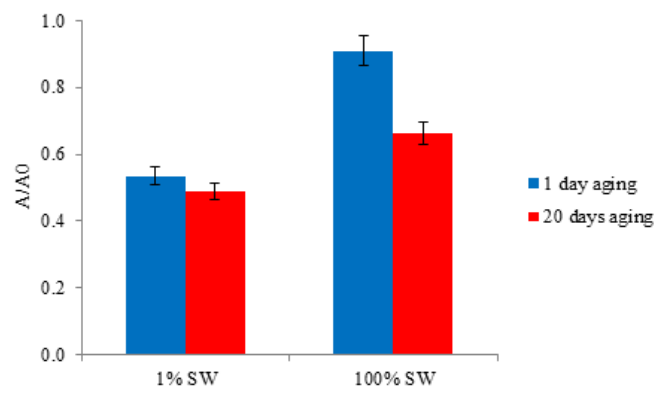

(c) S. aureus-Ti-R

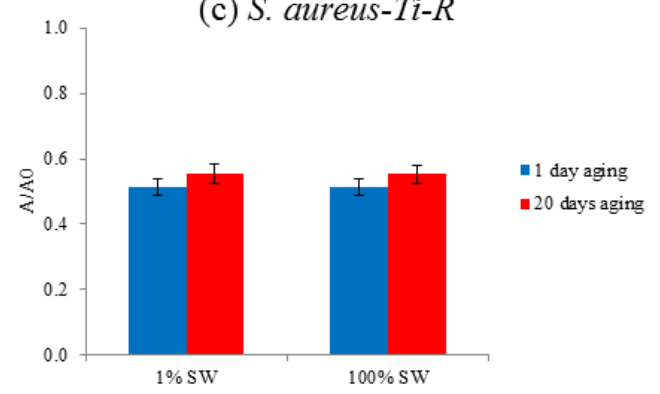

(d) $P$. aeruginosa/Ti-R

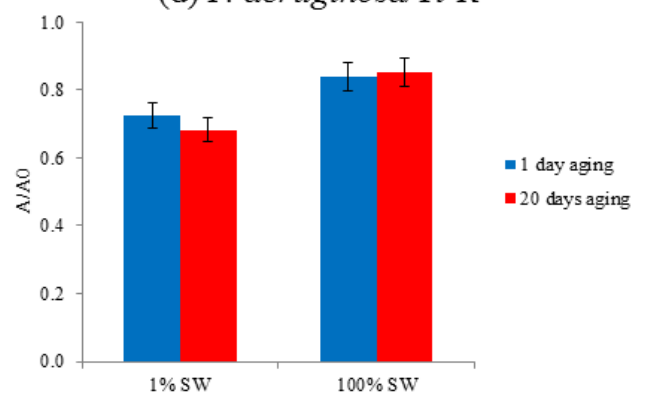

Figure 6. $\mathrm{LPO}$ responses of gram-negative and gram-positive bacteria to $\mathrm{TiO}_{2} \mathrm{NPs}$ with respect to age at different concentrations of sea-water $(n=5)$.

To determine the dominant effected biochemical response, tested biochemical parameters were evaluated to understand which one was affected the most. The significance order of inhibition pathways for $S$. aureus is LPO>antioxidant>protein>SOD, and antioxidant>protein when Ti-A NPs were aged in low and high concentration of seawater, respectively. On the other hand, the inhibition pathways were not specific for the $S$. aureus in the low concentration seawater aged Ti-R and tested parameters affected the inhibition similarly. Ti-R aged in high concentration seawater caused inhibition for $S$. aureus only via LPO activity. The significance order of inhibition pathways for $P$. aeruginosa are LPO $>$ protein and LPO $>$ SOD $>$ antioxidant for Ti-A aged in low and high seawater concentration, respectively. Ti-R aged in low and high seawater concentration inhibited P. aeruginosa via SOD>protein>LPO and only LPO, respectively.

\section{Conclusions}

The present study investigated the effect of test conditions, such as seawater concentration and aging, on the bacterial bioassay responses under influence of $\mathrm{TiO}_{2} \mathrm{NPs}$. For this purpose, physicochemistry of $\mathrm{TiO}_{2} \mathrm{NPs}$ and biochemical phenomena of test bacteria were evaluated. The main physicochemical properties of $\mathrm{TiO}_{2} \mathrm{NPs}$ indicated that zeta potentials and particle sizes of $\mathrm{TiO}_{2} \mathrm{NPs}$ were mostly influenced by aging duration and media concentration due to the alterations in surface from test media compared to control. On the other hand, while the viability of tested bacteria reduced remarkably in seawater, but aging duration slightly influenced the bioassay responses and the viability showed $\mathrm{TiO}_{2}$ 
NPs form-depended response. Also, the key events of the bacterial bioassay response were affected not only by physicochemical properties but also by biochemical properties.

As a conclusion, these results indicated that bacterial bioassay responses can influence from the test conditions, such as aging duration and seawater concentration.

\section{Supporting Information}

Supporting information accompanies this paper on http://www.acgpubs.org/journal/ journalof-chemical-metrology

\section{ORCID}

Asli Baysal: 0000-0002-0178-7808

Hasan Saygin: 0000-0003-2479-7635

Gul S. Ustabasi: 0000-0003-1828-5297

\section{References}

[1] A. Baysal, H. Saygin and G.S. Ustabasi (2020). An insight into the dependency on sample preparation for (eco) toxicity assessment of $\mathrm{TiO}_{2}$ nanoparticles, Environ. Monit. Assess. 192, 144. doi: 10.1007/s10661-020$8107-7$

[2] W. Fan, H. Lu and W.X. Wang (2018) Aging influences on the biokinetics of functional $\mathrm{TiO}_{2}$ nanoparticles with different surface chemistries in Daphnia magna, Environ. Sci. Technol. 52(14), 7901-7909.

[3] A. Baysal, H. Saygin and G. S. Ustabasi (2020) Age-related physicochemical differences in $\mathrm{ZnO}$ nanoparticles in the seawater and their bacterial interaction, Environ. Monit. Assess. 192(276), 1-11.

[4] A. Baysal and H. Saygin (2020). Smart nanosensors and methods for detection of nanoparticles and their potential toxicity in air, in: A. Amrane, A. Assadi, P. Nguyen-Tri, T. A. Nguyen, S. Rtimi (Eds) Nanomaterials for Air Remediation, 33-59.

[5] F. Seitz, S. Lüderwald, R.R. Rosenfeldt, R. Schulz and M. Bundschuh (2015). Aging of $\mathrm{TiO}_{2}$ nanoparticles transiently increases their toxicity to the pelagic microcrustacean Daphnia magna,PLoS ONE. 10(5), e0126021.

[6] H. Dong, F. Zhao, G. Zeng, L. Tang, C. Fan, L. Zhang, Y. Zeng, Q. He, Y. Xie and Y. Wu (2016) Aging study on carboxymethyl cellulose-coated zero-valent iron nanoparticles in water: Chemical transformation and structural evolution, J. Hazard. Mater. 312, 234-242.

[7] A. Baysal, H. Saygin and G.S. Ustabasi GS (2020) Importance of sample pretreatment on the bacterial bioassay for toxicity of $\mathrm{ZnO}$ nanoparticles. J. Chem. Metrol. 14(1), 12-24.

[8] R. Hjorth, P.A. Holden, S. F. Hansen, B. P. Colman, K. Grieger and C. Ogilvie Hendren (2017) The role of alternative testing strategies in environmental risk assessment of engineered nanomaterials, Environ. Sci. Nano, 4, 292-301.

[9] J. Labille, J. Feng, C. Botta, D. Borschneck, M. Sammut, M. Cabie, M. Auffan, J. Rose and J.Y. Bottero (2010) Aging of TiO(2) nanocomposites used in sunscreen. Dispersion and fate of the degradation products in aqueous environment, Environ. Pollut. 158(12), 3482-3489.

[10] H. Lu, H. Dong, W. Fan, J. Zuo and X. Li (2017) Aging and behavior of functional $\mathrm{TiO}_{2}$ nanoparticles in aqueous environment, J. Hazard. Mater. 32, 113-119.

[11] R.R. Rosenfeldt, F. Seitz, A.C. Haigis, J. Höger, J.P. Zubrod, R. Schulz and M. Bundschuh (2016) Nanosized titanium dioxide influences copper-induced toxicity during aging as a function of environmental conditions, Environ. Toxicol. Chem. 35(7), 1766-1774.

[12] D. Cupi, N.B. Hartmann and A. Baun (2015) The influence of natural organic matter and aging on suspension stability in guideline toxicity testing of silver, zinc oxide, and titanium dioxide nanoparticles with Daphnia magna, Environ. Toxicol. Chem. 34(3), 497-506.

[13] X. Lin, J. Li, S. Ma, G. Liu, Y. Yang, M. Tong and D. Lin (2014) Toxicity of $\mathrm{TiO}_{2}$ nanoparticles to Escherichia coli: effects of particle size, crystal phase and water chemistry, PLOS ONE. 9(10), e110247.

[14] N. Padmavathy and R. Vijayaraghavan (2011). Interaction of $\mathrm{ZnO}$ nanoparticles with microbes-A physio and biochemical assay, J. Biomed. Nanotechnol. 7, 1-10.

[15] D.A. Pelletier, A.K. Suresh, G.A. Holton, C.K. McKeown, W. Wang, B. Gu, N.P. Mortensen, D.P. Allison, D.C. Joy, M.R. Allison, S.D. Brown, T.J. Phelps and M.J. Doktycz (2010) Effects of engineered cerium oxide nanoparticles on bacterial growth and viability, Appl. Environ. Microbiol. 76(24), 7981-7989. 
[16] A. Arora, J. Jain, J.M. Rajwade, and K.M. Paknikar (2008). Cellular responses induced by silver nanoparticles: In vitro studies, Toxicol. Lett. 179, 93-100.

[17] R. Apak, K. Guclu, M. Ozyurek and S.E. Karademir (2004). Novel total antioxidant capacity index for dietary polyphenols and vitamins $\mathrm{C}$ and $\mathrm{E}$, using their cupric ion reducing capability in the presence of neocuproine: CUPRAC method, J. Agr. Food Chem. 52, 7970-7981.

[18] Y. Kono (1978) Generation of superoxide radical during autoxidation of hydroxylamine and an assay for superoxide dismutase, Arch. Biochem. Biophys. 186, 189-195.

[19] A. Baysal, H. Saygin and G. S. Ustabasi (2018). Interaction of PM2.5 airborne particulates with $\mathrm{ZnO}$ and $\mathrm{TiO}_{2}$ nanoparticles and their effect on bacteria, Environ. Monit. Assess. 190(1), 34-49.

[20] A. Baysal, H. Saygin and G. S. Ustabasi (2018). Influence of environmental media on carbon nanotubes and graphene nanoplatelets towards bacterial toxicity, Arch. Environ. Prot. 44(3), 85-98. .

[21] A. Baysal, H. Saygin and G. S Ustabasi (2019). Physicochemical transformation of $\mathrm{ZnO}$ and $\mathrm{TiO}_{2}$ nanoparticles in sea water and its impact on bacterial toxicity, Environ. Health Eng. Manag. J. 6(1), 73-80.

[22] A. Baysal and H. Saygin (2019). Physico-chemical and toxicological behaviour of $\mathrm{Al}_{2} \mathrm{O}_{3}$ nanoparticles in fine particulate matter, Environ. Eng. Manag. J. 18 (12), 2683-2694.

[23] F. Mallerve, C. Alba, C. Milne, S. Gillespie, T.F. Fernandes and T.J. Aspray (2016) Toxicity testing of pristine and aged silver nanoparticles in real wastewaters using bioluminescent Pseudomonas putida, Nanomaterials. 6(3), 49.

[24] H. Zhang, Q. Huang, A. Xu and L. Wu (2016) Spectroscopic probe to contribution of physicochemical transformations in the toxicity of aged ZnO NPs to Chlorella vulgaris: new insight into the variation of toxicity of ZnO NPs under aging process, Nanotoxicology 10(8), 1177-87.

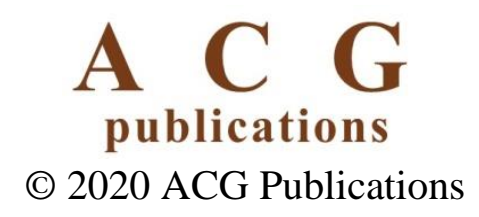

